\title{
Spearmint (Mentha spicata L.) essential oil from tipaza (Algeria): in vivo anti-inflammatory and analgesic activities in experimental animal models
}

\author{
SARAH KEHILI ${ }^{1}$, MOHAMED NADJIB BOUKHATEM ${ }^{2 *}$, ASMA BELKADI ${ }^{3}$, \\ FAIZA BOULAGHMEN ${ }^{4}$, MOHAMED AMINE FERHAT ${ }^{1}$, WILLIAM N. SETZER ${ }^{5,6}$ \\ ${ }^{1}$ Laboratory of Research on Bio-Active Products and Valorization of Biomasse, Department of Chemistry, Ecole Normale Superieure, \\ Algiers, Algeria \\ ${ }^{2}$ Department of Biology and Cell Physiology, Faculty of Life and Natural Sciences, University - Saad Dahlab - Blida 1, Blida, Algeria \\ ${ }^{3}$ Laboratory of Pharmacology and Toxicology, Research and Development Center, SAIDAL Pharmaceuticals, Algiers, Algeria \\ ${ }^{4}$ Anatomic Pathology Laboratory, Hospital - Dr Fares Yahia - Kolea, Tipaza, Algeria \\ ${ }^{5}$ Department of Chemistry, University of Alabama in Huntsville, Huntsville,USA \\ ${ }^{6}$ Aromatic Plant Research Center, Lehi, USA
}

*Corresponding Author: Mohamed Nadjib Boukhatem

Email:mn.boukhatem@yahoo.fr

Received: 13 March 2020 / Revised: 6 April 2020 / Accepted: 8 April 2020

\begin{abstract}
Introduction: Although analgesic and nonsteroidal anti-inflammatory drugs (NSAIDs) are usually used to treat a diversity of illnesses, their administration is linked with acute kidney injury and gastrointestinal side effects. The research of new biomolecules and natural products is still needed such as medicinal plants.

Aims: The present research was aimed to investigate, for the first time, the anti-inflammatory and anti-nociceptive effects of spearmint essential oil (SEO) in mouse models of acute inflammation and pain.

Materials and Method: Chemical analysis of SEO was done by gas chromatography. The anti-inflammatory activity was tested using two models of acute inflammation namely carrageenan-induced paw edema and xylene-induced ear edema. Histological examination of both non-inflamed and inflamed tissues was evaluated. The anti-nociceptive activity was tested using the pain model induced by acetic acid.

Results: The main constituent of the SEO was found to be carvone (52.60\%). The SEO exhibited a promising anti-inflammatory effect as demonstrated by statistically significant ( $p<0.05$ ) inhibition of paw volume by $77.24 \%$ at the dose of $20 \mu \mathrm{L} / \mathrm{kg}$ and $65.87 \%$ at the dose of $200 \mu \mathrm{L} / \mathrm{kg}$. Furthermore, topical administration of the SEO inhibited xylene-induced ear edema in comparison with the control group $(p<0.05)$. The higher dose $(200 \mu \mathrm{L} / \mathrm{kg})$ significantly $(p<0.001)$ reduced xylene-induced ear edema which was similar to that observed with positive control (ketoprofen). The pathological analysis of the paws and ears revealed that SEO was capable of reducing cellular infiltration and subcutaneous edema. Else, the SEO produced significant anti-nociceptive activity $(p<0.001)$ at higher dose by inhibiting spontaneous nociception.

Conclusion: These results support the use of SEO in the development of pharmaceuticals for the management of inflammation and pain.
\end{abstract}

Keywords: Spearmint essential oil; Anti-inflammatory effect; Carvone; Histological analysis; anti-nociceptive activity.

Abbreviations: ANOVA = Analysis of variance; COX-2 = Cyclooxygenase-2; EO = Essential oil; GC-MS = Gas Chromatography-Mass Spectrometry; H\&E = Hematoxylin-Eosin; IL= Interleukin; iNOS = Nitric Oxide Synthase; INF- $\gamma=$ Interferon; IC50 = Median inhibitory concentration; LPS = Lipo-polysaccharide ; LTB4 = Leukotriene B4 ; NIH = National Institute of Health; NIST = National Standard Institute Technology; NSAIDs = Nonsteroidal Anti-Inflammatory Drugs; NV = Neovascularization; p.o. = per os; PBS = Phosphate-buffered saline; PGE2 = Prostaglandin E2; SEO = Spearmint essential oil; PMN = Polymorphonuclear cells'; RT = Retention Times; SD = Standard Deviation; TNF = Tumor Necrosis Factor. 


\section{Introduction}

Inflammation is an imperative biological reaction which happens in answer to a varied range of injurious agents such as physical trauma, bacterial infection, chemicals or any additional physical phenomenon. Inflammation is the complex state of hyperemia from blood vessels with resulting warmness, redness, swelling and discomfort [1]. Immune reaction is important for the body to eliminate and remove hazardous pathogens by way of an acute inflammation [2]. Inflammation usually implicates edema and pain at the location of injury or wound due to discharge of many proinflammatory chemical mediators along with the escape of liquid from the vascular tissues due to increase in the penetrability of the vessel barriers, tissue damage, infiltration and migration of inflammatory cells and healing [3]. All kinds of pain, whether it is chronic or acute, initiate from inflammation. During inflammation, several proinflammatory chemical factors such as interferon (INF- $\gamma$ ), tumor necrosis factor (TNF), cyclooxygenase-2 (COX-2), interleukins (IL-6 and IL-12), and inducible nitric oxide synthase (iNOS) are synthetized and secreted. The receptors involved in inflammation are similarly stimulated in pain [4].

Non-steroidal anti-inflammatory drugs (NSAIDs), such as diclofenac sodium, are among the most frequently recommended medications due to their regular efficiency in the management and treatment of inflammation, pain and rheumatic complaints [5]. Nevertheless, their administration is linked with undesirable effects at the level of digestive area, ranging from gastrointestinal erosions and severe peptic ulcers to more grave problems, such as over bleeding or full damage of epithelial membrane. Other NSAIDs adverse reactions comprise hepatic, renal and cardiovascular undesirable effects which are correlated to the agent as well as the frequency and period of treatment [6]. Then, to overcome the toxicity of NSAIDs, the investigation of new and promising molecules is still required and the natural products such as aromatic and medicinal plants could lead in the development of new anti-inflammatory and analgesic drugs with fewer side effects.

Numerous species of Mentha genus are used in phytotherapy as flavor agents and as herbal medicines for several human therapeutic administrations [7]. Spearmint (Mentha spicata L.) is generally cultivated in different regions worldwide to com- mercially produce its aromatic or essential oil (EO) [8]. Spearmint has several therapeutic properties and health benefits and is used in phytomedicine as antifungal, diuretic, carminative and antioxidant agents, and for management of colds and flu, hemorrhoids, respiratory tract problems and stomach ache. Interestingly, spearmint essential oils (SEOs) were recognized as rich in oxygenated monoterpenes and were found to have antimicrobial activity $[9,10]$. It is also a nontoxic and real therapeutic choice for the cure of chemotherapy-induced emesis and nausea in patients [11].

Although several studies have been reported on the chemical composition, antimicrobial and antioxidant activities of spearmint essential oil in vitro [7-10], however only few investigations report its pharmacological effects in vivo. Based on the above reflections, the present research reports, for the first time, the chemical composition of essential oil obtained from the leaves and stems of spearmint grown in Algeria as well as the in vivo anti-inflammatory and anti-nociceptive effects.

\section{Material and methods}

\subsection{Materials}

\subsubsection{Extraction of Spearmint essential oil}

Spearmint (Mentha spicata L.) leaves and stems were collected on june 2016 in the Cherchell region (Tipaza, Algeria). This area is located in the eastern region of Algiers (coordinates 35 $52^{\prime} 34^{\prime \prime} \mathrm{N}$ latitude and $0^{\circ} 17^{\prime} 20^{\prime \prime} \mathrm{W}$ longitude). SEO was extracted from the aerial part of spearmint with and alembic steam distillation (Extral-Bio company, Chiffa, Blida, Algeria). The whole quantity of fresh plant used was $450 \mathrm{~kg}$, and it was loaded in the still and stacked in layers to allow appropriate delivery of the steam. The process consists of passing water vapor at a high-pressure through an alembic (tank) filled with spearmint. The SEO was stored in a sealed vial, at $4{ }^{\circ} \mathrm{C}$, before use.

\subsubsection{Chemicals and drugs}

The following drugs and chemicals were used: dimethyl sulfoxide (DMSO), sodium diclofenac, carrageenan, xylene, tween 80 , isosaline $(0.85 \%)$ and phosphate-buffered saline (PBS) solutions were purchased from Sigma Chemical Co. (St. Louis, MO, USA). Ketum gel ${ }^{\circledR}$ 2.5\% (Ketoprofene 60 g, 
Laboratoire Menarini, Barcelona, Spain), Spasfon ${ }^{\circledR}$ 80 mg (Phloroglucinol, Teva Sante, Paris, France), Ketamile $^{\circledR}$ (Ketamine chlorydrate, El Kendi Pharmaceuticals, Algiers, Algeria) and Votrex ${ }^{\circledR} 50 \mathrm{mg}$ (sodium diclofenac, Hikma Pharmaceuticals, Jordan) were also used.

\subsubsection{Animals}

Swiss NMRI male mice $(25.28 \pm 1.75 \mathrm{~g})$ were got from the animal breeding of SAIDAL pharmaceutical company (Algiers, Algeria). The mice were used in agreement with the guiding principles in the care and use of animals agreed by the Council of the American Physiologic Society. The mice were permitted free access to water and food under conditions of optimum light (12 hours lightdark cycle) with the room temperature maintained at $25 \pm 3{ }^{\circ} \mathrm{C}$ and relative humidity of $45-60 \%$. In anti-inflammatory and analgesic assays, mice were arbitrarily separated into five groups: control, NSAID, and SEO (200, 20, and $2 \mu \mathrm{L} / \mathrm{kg}$ ) groups. All experiments were done between 9:00 a.m. and 3:00 p.m. All labors were done in order to diminish animal suffering.

\subsection{Methods}

\subsubsection{Determination of the chemical composition of spearmint essential oil}

The chromatographic analysis of the SEO was done using a Shimadzu gas chromatograph (Shimadzu Corporation, Kyoto, Japan), coupled with a Shimadzu mass spectrometer detector QP-5050A. The GC-MS system was equipped with a Tracsil Meta.X5 column, 95\% polydimethylsiloxane and $5 \%$ polydiphenylsiloxane (Teknokroma S. Coop. C. Ltd., Barcelona, Spain; $60 \mathrm{~m} \times 0.25 \mathrm{~mm} \times 0.25 \mu \mathrm{m}$ film thickness). Analysis was done using $\mathrm{He}$ as carrier gas at a column flow of $0.3 \mathrm{~mL} / \mathrm{min}$ with a split ratio of 1:200. The oven temperature program was as follow: (a) $80{ }^{\circ} \mathrm{C}, 0 \mathrm{~min}$; (b) rate of $4{ }^{\circ} \mathrm{C} / \mathrm{min}$ from 80 to $210{ }^{\circ} \mathrm{C}$ and hold for $1 \mathrm{~min}$; (c) rate of 25 ${ }^{\circ} \mathrm{C} / \mathrm{min}$ from 210 to $300{ }^{\circ} \mathrm{C}$ and hold for $8 \mathrm{~min}$. The temperatures of the injector and detector were 230 and $300{ }^{\circ} \mathrm{C}$, respectively. All chemical compounds were detected and identified using two different techniques: (1) mass spectra (NIST05 spectral library collection), and (2) comparison of their experimental retention indices (RI) with those of the literature. Only fully identified compounds are reported in this study.

\subsubsection{In vivo anti-inflammatory activity}

\subsubsection{Carrageenan-induced paw edema in mice}

Carrageenan-induced paw edema in mice is a well-established technique of acute inflammation for evaluation of anti-inflammatory molecules. This method was similar to that reported by Mogosan et al. [12]. Mice (six weeks old) weighing about $24-27 \mathrm{~g}$ were randomly divided into five groups of six animals; including a control group (vehicle, isosaline $\mathrm{NaCl} 0.9 \%$ ); SEO groups $(2,20$ and $200 \mu \mathrm{L} / \mathrm{kg}$ ), and NSAIDs group (diclofenac sodium, $50 \mathrm{mg} / \mathrm{kg}$ ), as the standard drug. The designated groups were orally treated with vehicle, SEO, or NSAIDs 40 minutes before $\lambda$-carrageenan injection. For induction of inflammation, the mice received an injection of $100 \mu \mathrm{L}$ of $1 \%(\mathrm{w} / \mathrm{v})$ suspension of $\lambda$-carrageenan in saline, into the mousess plantar side of the left hind paw after $40 \mathrm{~min}$ of the oral administration of the sample. The animals were sacrificed 4 hours later. The difference in weight between right untreated and left treated hind paws was calculated and results are expressed as the increase in paw weight $(\mathrm{mg})$. The percentage inhibition of the inflammatory response was calculated by comparison to the negative control and SEO or NSAIDS groups by using this formula:

$\%$ Inhibition of edema $=\left(\frac{\left(C_{t}-C_{0}\right) \text { Control }-\left(C_{t}-C_{0}\right) \text { Treated }}{\left.\left(C_{t}^{-} C_{0}\right) \text { Control }\right)}\right) \times 100$

Where $\left(C_{t}-C_{0}\right)$ control is the difference in the weight of paw at 4 hours in control animal, and $\left(\mathrm{C}_{\mathrm{t}}-\mathrm{C}_{0}\right)$ treated is the difference in the weight of paw at 4 hours in animal treated either with the standard drug or SEO.

At the end of the assay, the mice were euthanized by diethyl ether and the inflamed paws were removed and fixed in 10\% formaldehyde solution for histological analysis and examination.

\subsubsection{Histological examination of mouse paw tissue}

To further confirm the inflammatory changes in paw of animals after injection of carrageenan, the mice were sacrificed $4 \mathrm{~h}$ after the generation of inflammation. The sub-plantar paw tissue samples were then removed, fixed in $10 \%$ neutralized formalin for $24 \mathrm{~h}$, dehydrated with alcohol (ethanol), surrounded in paraffin wax $\left(56^{\circ} \mathrm{C}\right)$ and cut into 5 $\mu \mathrm{m}$ thick sections. Successive sections were stained with haematoxylin and eosin (H\&E) stain 
to establish the degree of edema and inflammation [13]. The stained sections were examined under a light microscope and the histological modifications were registered with the assistance of a pathologist. The severity of paw tissue inflammation was evaluated by two independent observers blinded to the method protocol.

\subsubsection{Xylene-induced mice ear edema}

Topical inflammation was done using ear edema model according to the method of Boukhatem et al. [13]. Adult Swiss albino mice were arbitrarily divided into five groups, each containing six mice. The acute inflammation was made on the posterior and anterior surfaces of the right ear by the topical application of $20 \mu \mathrm{L} /$ ear of xylene. The left ear (untreated) was considered as a control. To determine the topical anti-inflammatory effect, SEO diluted in almond oil was applied topically at different doses (200, 20 and $2 \mu \mathrm{L} / \mathrm{kg}$ ) 40 minutes before the xylene application. Another group was treated only with vehicle (almond oil) and was considered as a control. Ketoprofen (NSAIDs) was used as a reference drug. Four hours after the application of xylene, the animals were sacrified and two ear punches (6 $\mathrm{mm}$ diameter) were taken from from both untreated (left) and treated (right) ears and weighed. The weight difference between the right and left ear disks of the same mice was assessed as the intensity of edema. The anti-inflammatory effect was estimated and expressed as a percentage reduction of edema in treated mice compared with the control and calculated using the following formula:

$$
\% \text { Inhibition of topical edema }=\left(1-\frac{\Delta \mathrm{Wt}}{\Delta \mathrm{Wc}}\right) \times 100
$$

where $\Delta \mathrm{Wt}$ is the change in weight of ear tissue in the treated mice, and $\Delta W_{c}$ the change in weight of ear tissue in the control mice (vehicle).

\subsubsection{Histological examination of mouse ear tissue}

The subsequent inflammatory response was assessed and monitored by estimation of edema formation and by microscopic observation. For the histological study of cutaneous inflammation, two samples of the swollen ears from the control and the SEO treated groups were removed and fixed in $10 \%$ formaldehyde for one week. Then, the fixed ear tissues were implanted in paraffin, routinely processed and sectioned at $5 \mu \mathrm{m}$ using a microtome (LEICA RM, Nussloch, Germany). The slices were mounted on the glass slides, stained with H\&E and lastly observed and examined by a pathologist in a blinded way. The ear tissues were observed with a light microscope (Olympus CX41) and graded as minor $(+)$, modest $(++)$, or severe $(+++)$ for inflammation phase. Infiltration and polymorphonuclear (PMN) cells' accumulations and infiltration were also reported [13]. The histological examination was carried out in the laboratory of histopathology, Hospital of Kolea (Tipaza city, Algeria).

\subsubsection{In vivo anti-nociceptive activity of SEO using acetic acid-induced writhing test}

The anti-nociceptive activity of SEO was investigated using the writhing assay (abdominal constriction test), according to the method of Mogosan et al. [12]. A total number of 30 male mice were divided into five groups. Briefly, mice were treated orally with phloroglucinol (Spasfon $80^{\circledR}$ $\mathrm{mg} / \mathrm{kg}$, i.p.) which is considered as a standard analgesic drug. Also, SEO and vehicle (isosaline, $\mathrm{NaCl} 0.9 \%$ ) were administrated orally $30 \mathrm{~min}$. After that, intra-peritoneal injection of acetic acid $(0.6 \%)$ was done for the induction of abdominal contractions. The number of abdominal contractions or writhes were counted for each group of mice starting from one minute after the injection of acetic acid up to 10 minutes and expressed as percent protection. The anti-nociceptive activity was estimated as the percentage of inhibition of abdominal contractions between the control and the treated groups (SEO or standard drug) using the following formula:

$$
\text { Protection (\%) }=\left(\frac{N_{c}-N_{t}}{N_{c}}\right) \times 100
$$

Where $\mathrm{N}_{\mathrm{c}}$ is number of writhing in control, and $\mathrm{N}_{\mathrm{t}}$ is the number of writhing in test mice.

\subsubsection{Statistical analysis}

Data obtained in our research was presented as mean \pm SD where each value represents a minimum of 6 mice. One way analysis of variance (ANOVA) was done to evaluate the variability among groups. Significant differences among groups were calculated using Tukey's multiple comparison tests in which the results were compared with that of control group. The results were considered statistically significant at $p<0.05$. XLSTAT software 2014 for Windows (Addinsoft, Paris, France) was used for all statistical analysis. 


\section{Results and discussion}

\subsection{Chemical composition of spearmint essential oil using GC-MS analysis}

The EO was extracted by steam distillation from the dried aerial parts of spearmint from the Cherchell region (Tipaza, Algeria), and was analyzed by GC-MS (Figure 1 shows a representative chromatogram). The SEO showed a diverse composition with 19 constituents reported in Table I The most abundant chemical components were oxygenated monoterpenes $64.7 \%$, followed by monoterpene hydrocarbons ( $28.84 \%)$, and sesquiterpene hydrocarbons $(6.46 \%)$. The main constituents were carvone $(52.60 \%)$ and limonene $(24.99 \%)$, followed by 1.8 -cineole $(7.22 \%)$ and trans-caryophyllene $(3.38 \%)$. Other chemical compounds were detected but were less than $3 \%$.

The EO of this Algerian variety of mint can be ascribed to the carvone/limonene chemotype. Actually, there is great variation in the chemical composition of spearmint, cultivated as well as endemic or wild, around the world. Remarkably, our SEO seems to be richer with some main compounds such as eucalyptol (1.8-cineole) and oxygenated monoterpenes. A review of the literature accessible on this theme shows that several articles have previously been published on SEOs chemical composition $[10,11]$. In addition, our findings about most major chemical constituents of SEO collected from the center part of Algeria are in agreement with previous reports [8,9]. Govindarajan et al. [14] studied the chemical composition of SEO obtained from

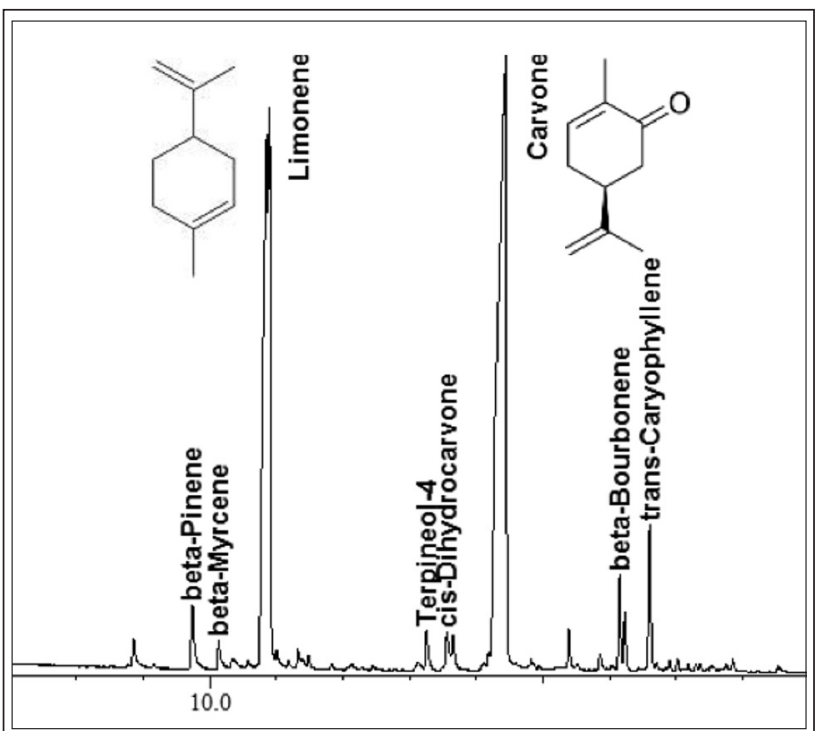

Figure 1 Chromatogram of SEO analysed with GC-MS.
Table I Chemical composition of Algerian Mentha spicata (L.) essential oil using GC-MS.

\begin{tabular}{c|l|r}
\hline RT (min) & \multicolumn{1}{|c|}{ Name } & \multicolumn{1}{c}{$\%$} \\
\hline 8.855 & $\alpha$-Pinene & 0.66 \\
\hline 9.742 & $\beta$-Pinene & 1.97 \\
\hline 10.132 & $\beta$-Myrcene & 0.77 \\
\hline 10.853 & Limonene & 24.99 \\
\hline 10.899 & 1.8 -Cineole & 7.22 \\
\hline 11.178 & $\beta$-Ocimene & 0.10 \\
\hline 11.324 & $\gamma$-Terpinene & 0.35 \\
\hline 11.487 & cis-Terpineol & 0.16 \\
\hline 13.253 & Terpineol-4 & 1.22 \\
\hline 13.562 & cis-Dihydrocarvone & 1.06 \\
\hline 13.655 & Dihydrocarveol & 0.88 \\
\hline 14.187 & Pulegone & 0.38 \\
\hline 14.442 & Carvone & 52.60 \\
\hline 15.392 & Dihydrocarvyl acetate & 0.82 \\
\hline 15.858 & cis-Carvyl acetate & 0.36 \\
\hline 16.154 & $\beta$-Bourbonene & 1.87 \\
\hline 16.234 & $\beta$-Elemene & 0.96 \\
\hline 16.610 & trans-Caryophyllene & 3.38 \\
\hline 17.022 & $\alpha$-Humulene & 0.25 \\
\hline & Oxygenated Monoterpenes & $\mathbf{6 4 . 7}$ \\
\hline & Monoterene Hydrocarbons & $\mathbf{2 8 . 8 4}$ \\
\hline & Sesquiterpene Hydrocarbons & $\mathbf{6 . 4 6}$ \\
\hline
\end{tabular}

Tamilnadu (India) and reported carvone (48.60) and limonene $(11.30 \%)$ as the dominant compounds. Padalia et al. [15] reported the chemical composition of 16 cultivars of Chinese Mentha species and revealed that carvone $(51.3 \%-65.1 \%)$ and limonene $(15.1 \%-25.2 \%)$ are the principal compounds in five cultivars of spearmint. In contradiction with our data, Telci et al. [16] studied chemical composition and antimicrobial effect of SEO and demonstrated that piperitone and pulegone were the main components. Else, El-Sayed et al. [17] confirmed that menthone $(32.43 \%)$ and eucalyptol $(18.79 \%)$ were the dominant constituents of the Egyptian SEO. Further, a linalool-rich chemotype $(82.8 \%)$ was described from Turkey [18].

Usually, the observed changes in chemical composition of SEO, when compared with earlier reports, could be linked to different abiotic or biotic factors comprising several extraction methods, climate and seasonal variations, geographical conditions, relative humidity, agronomic conditions (harvesting time, crop density, organic fertilizers), genotype, stage of the plant growth and processing of plant materials before distillation of the SEO [19]. 


\subsection{In vivo anti-inflammatory activity}

\subsubsection{In vivo anti-inflammatory activity using carrageenan-induced paw edema test}

The anti-inflammatory effect of medicinal herbs has been confirmed and few others refuted. Therefore the present research is carried out with a purpose to screen the effectiveness of anti-inflammatory potential of SEO in experimental animals. The acute inflammation was experimentally made by carrageenan to evaluate the anti-inflammatory property of SEO in mice. Subcutaneous injection of carrageenan produced an increase in animal paw weight due to edema, thus demonstrating acute inflammation.

As shown in Table II, SEO showed an interesting anti-inflammatory potential. At 4 hours after oral administration of SEO, the weight of treated left hind paw was similar for $200 \mu \mathrm{L} / \mathrm{kg}$ and $20 \mu \mathrm{L} / \mathrm{kg}$ (3.7 $\pm 6.3 \mathrm{mg}$ and $02.5 \pm 3.48 \mathrm{mg}$, respectively) with edema inhibition values of $65.87 \%$ and $77.24 \%$. This level of edema inhibition was similar to the level detected using $50 \mathrm{mg} / \mathrm{kg}$ of the standard reference drug $(85.32 \%)$. Our findings revealed that treatment with SEO was effective in decreasing the edema induced by carrageenan. However, the drug used as a reference (sodium diclofenac) was more effective in preventing these effects.

The carrageenan-induced paw edema assay is the most commonly used test to determine new anti-inflammatory molecules or drugs. This model is greatly reproducible and has been well recognized as an effective technique to investigate proinflammatory cytokine generation and mediators (serotonin, histamine, prostaglandins and bradykinin) in the paw tissue in inflammatory situations $[12,20]$.

Our investigation presents a primary research and additional studies are needed to explain the effect and mechanism of action of the SEO components. Several studies reported that the anti-inflammatory activities obtained with SEO might be related to some anti-inflammatory molecules such as oxygenated monoterpenes (carvone and eucalyptol) $[20,21]$. In fact, D-carvone inhibited the animal hind paw edema induced by various phlogistics (histamine, carrageenin, dextran and bradykinin) in a dose-dependent manner [20].

In addition, it has been reported that mint oil also prevents the inflammatory consequences of Lipo-polysaccharide (LPS), together with inhibition of prostaglandin E2 (PGE2), interleukin-1 (IL1) and leukotriene B4 (LTB4) production by LPSstimulated human monocytes $[22,23]$.

\subsubsection{Histological examination of the mice paws after injection of carrageenan}

To confirm the anti-inflammatory effect of SEO histologically, paw biopsies were harvested $4 \mathrm{~h}$ after carrageenan had been injected. Paw tissues from all the groups of animal were examined by $H \& E$ staining. The control groups not induced by inflammation showed normal tissue (Figure 2A) with no inflammation, tissue destruction or swelling phenomenon in the paws of normal mice. On the other hand, the animal injected with carrageenan (Figure 2C) showed a strong edema and inflamed cavities in the paw tissue, characterized by congestion of blood vessels, dermal and epithelial tissue with an important number of infiltrated inflammatory cells detected in the paw tissue. The cell types were mostly neutrophils, which describe acute inflammation.

As for the positive (Figure 2B) and SEO groups (Figure 2D, E and F), edematous condition was clearly decreased by treatment with NSAID (diclofenac sodium, $50 \mathrm{mg} / \mathrm{kg})$ and SEO $(2,20$, and

Table II In vivo Effects of the spearmint EO (2, 20 and $20 \mu \mathrm{L} / \mathrm{kg})$ and diclofenac sodium (50 mg/kg) on carrageenan-induced paw edema in mice.

\begin{tabular}{c|c|c|c|c}
\hline Treatment & \multicolumn{3}{|c|}{ Weight (mean, mg) \pm SD } & \\
\hline & Left paw & Right paw & Edema weight \# & \% Inhibition of edema \\
\hline Negative control (Vehicle) & $140.2 \pm 18.72$ & $129.3 \pm 11.68$ & $10.9 \pm 15.19^{\mathrm{B}}$ & $/$ \\
\hline Positive control (NSAID) & $132.4 \pm 8.99$ & $130.8 \pm 10.00$ & $1.6 \pm 3.21^{\mathrm{A}}$ & 85.32 \\
\hline SEO 200 & $134.1 \pm 13.38$ & $130.4 \pm 17.54$ & $3.7 \pm 6.30^{\mathrm{AB}}$ & 65.87 \\
\hline SEO 20 & $139.7 \pm 12.39$ & $137.2 \pm 15.07$ & $2.5 \pm 3.48^{\mathrm{AB}}$ & 77.24 \\
\hline SEO 2 & $140.1 \pm 12.08$ & $132.9 \pm 18.34$ & $7.2 \pm 14.03^{\mathrm{AB}}$ & 33.57 \\
\hline
\end{tabular}

Groups of mice ( $n=6 /$ group) were pretreated with vehicle ( $\mathrm{NaCl}, 0.9 \%)$, NSAID: non-steroidal anti-inflammatory drugs (Sodium diclofenac, $50 \mathrm{mg} / \mathrm{kg}$, p.o.). SEO: Spearmint essential oil at doses of 2, 20, and $200 \mu \mathrm{L} / \mathrm{kg}$ (p.o.) \# Means within the same column followed by the same capital letter are not significantly different $(p>0.05)$ according to ANOVA one way analysis followed by Tukey's post hoc multiple comparison test. 


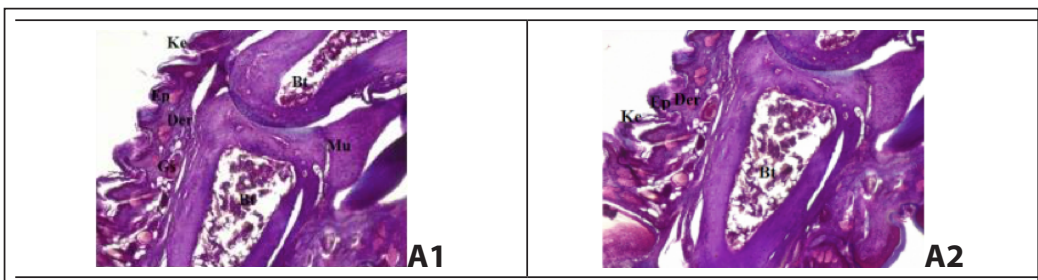

Right paw (control) (Gx10) = Edema (-); inflammatory cell infiltration (-), inflammation phase (-).

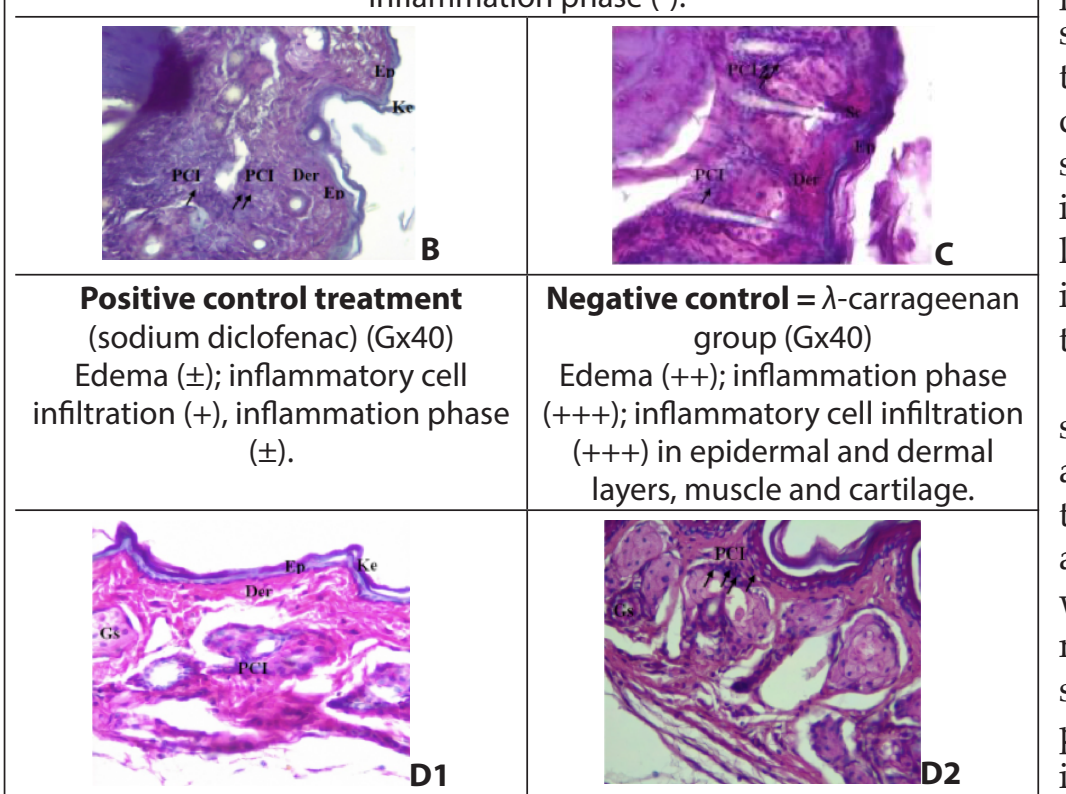

SEO treatment ( $2 \mu \mathrm{L} / \mathrm{Kg})(\mathrm{D} 1 \times 10 ; \mathrm{D} 2 \times 10)$

Edema ( \pm ); inflammatory cell infiltration $(+)$, inflammation phase $( \pm)$.

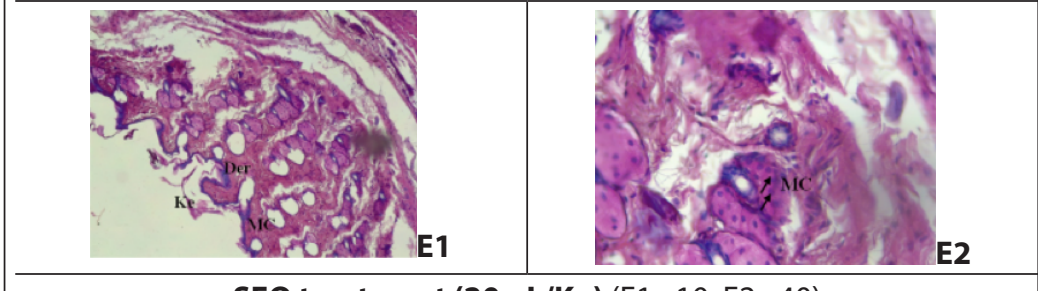

SEO treatment $(20 \mu \mathrm{L} / \mathrm{Kg})(\mathrm{E} 1 \times 10 ; \mathrm{E} 2 \times 40)$

Edema $( \pm)$; inflammatory cell infiltration $(+)$, inflammation phase $( \pm)$.

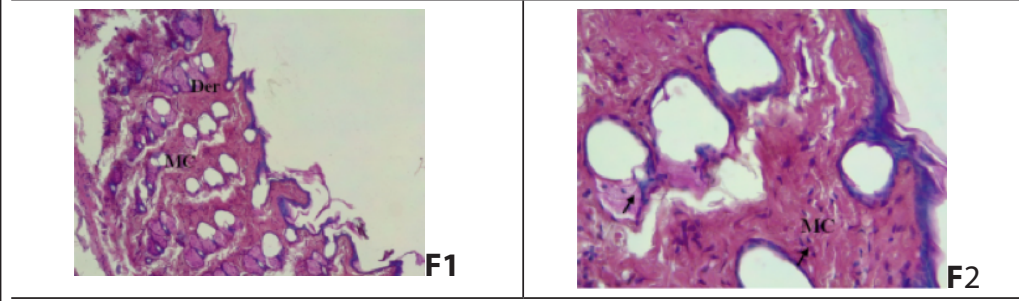

SEO treatment $(200 \mu \mathrm{L} / \mathrm{Kg})(\mathrm{F} 1 \times 10 ; \mathrm{F} 2 \times 40)$

Edema $( \pm)$; inflammatory cell infiltration $(+)$, inflammation phase $( \pm)$.

Ke: keratin; $\mathrm{Ep}=$ epidermal layer; $\mathrm{SC}=$ subcutaneous layer; $\mathrm{Bt}=$ bone tissue; $\mathrm{Mu}=$ muscle fibers; $\mathrm{Gs}=$ sebaceous gland; $\mathrm{PCl}=$ polymorphonuclear cells infiltration; $\mathrm{MC}=$ mononuclear cells; Ed: edema.

Figure 2 Histopathological examinations on $\lambda$-carrageenan-induced paw tissue swelling, edema and neutrophil infiltration. Light photomicrographs of the HEE stained paw tissue in the (A) control group (right paw), (B) NSAIDs group, (C) $\lambda$-carrageenan group, (D) SEO $(2 \mu \mathrm{L} / \mathrm{kg}),(E) S E O$ $(20 \mu \mathrm{L} / \mathrm{kg})$ and $(F)$ SEO $(200 \mu \mathrm{L} / \mathrm{kg})$ groups. Paws were harvested $4 \mathrm{~h}$ after injection of carrageenan and subjected to histochemical staining.
$200 \mu \mathrm{L} / \mathrm{kg}$ ) as well as a decrease in the infiltration of inflammatory cells. At higher dose of SEO, treated animals showed a better effect in decreasing of neutrophils as compared with standard drug (Figure 2F vs 2C).

Our findings clearly establish the property of SEO within the target tissue, giving additional confirmation that SEO reduces carrageenan-induced paw edema. Mogosan et al. [12] stated that the treatment of SEO inhibited the edema and decreases the cellular infiltrates probably by decreasing the inflammatory chemical mediators.

The histopathological findings also substantiate with the paw edema analyses. Histopathological examinations indicated that edema formation and, inflammatory cell infiltration were obviously suppressed in the animal treated with the SEO. These data support the results obtained from the paw edema test and confirm the antiinflammatory action of SEO against acute inflammation.

The use of current NSAIDs is frequently associated with severe and different side effects. Hence alternative therapeutic molecules are required. Few studies have been initiated around the world into researching, evaluating and analyzing the local medicinal plants with anti-edematous values. In spite of the medicinal potential of SEO, its effect on inflammation has not been previously reported in detail. Therefore, in the present study, we screened and confirmed for the first time the anti-inflammatory efficacy of SEO against carrageenan induced paw edema followed by histological analysis.

\subsubsection{In vivo anti-inflammatory activity using xylene-induced ear edema assay}

The anti-inflammatory effect of SEO was further assessed by the inhibition of xylene-induced ear edema. As shown in Table III, topical application of xylene in the control group caused 
Table III Effects of the SEO (2, 20 and $200 \mu \mathrm{L} / \mathrm{kg})$ and Ketoprofen (5 $\mathrm{mg} /$ ear $)$ on xylene-induced ear edema in mice.

\begin{tabular}{|c|c|c|c|c|}
\hline \multirow[t]{2}{*}{ Treatment } & \multicolumn{3}{|c|}{ Weight (mean, mg) \pm SD } & \multirow[b]{2}{*}{$\%$ inhibition of edema } \\
\hline & Right ear & Left ear & Edema weight \# & \\
\hline Negative control (Vehicle) & $9 \pm 0.44$ & $12.6 \pm 1.34$ & $3.6 \pm 1.14^{\text {в }}$ & - \\
\hline Positive control (NSAID) & $7.4 \pm 1.51$ & $7.8 \pm 1.09$ & $0.4 \pm 1.14^{\mathrm{A}}$ & 88.88 \\
\hline SEO $200 \mu \mathrm{L} / \mathrm{kg}$ & $8 \pm 0.83$ & $8.2 \pm 0.83$ & $0.2 \pm 0.54^{\mathrm{A}}$ & 94.44 \\
\hline SEO $20 \mu \mathrm{L} / \mathrm{kg}$ & $8 \pm 0.54$ & $8.4 \pm 0.54$ & $0.4 \pm 0.44^{\mathrm{A}}$ & 88.89 \\
\hline SEO $2 \mu \mathrm{L} / \mathrm{kg}$ & $7.4 \pm 0.89$ & $8.8 \pm 0.83$ & $1.4 \pm 1.14^{\mathrm{A}}$ & 61.11 \\
\hline
\end{tabular}

Groups of mice ( $\mathrm{n}=6$ /group) were pretreated with vehicle, NSAID: non-steroidal anti-inflammatory drug (Ketoprofen $2.5 \%$ ). SEO: Spearmint essential oil at doses of 2, 20, and $200 \mu \mathrm{L} / \mathrm{kg}$ (topically). \# Means within the same column followed by the same capital letter are not significantly different $(p>0.05)$ according to ANOVA one way analysis followed by Tukey's post hoc multiple comparison test.

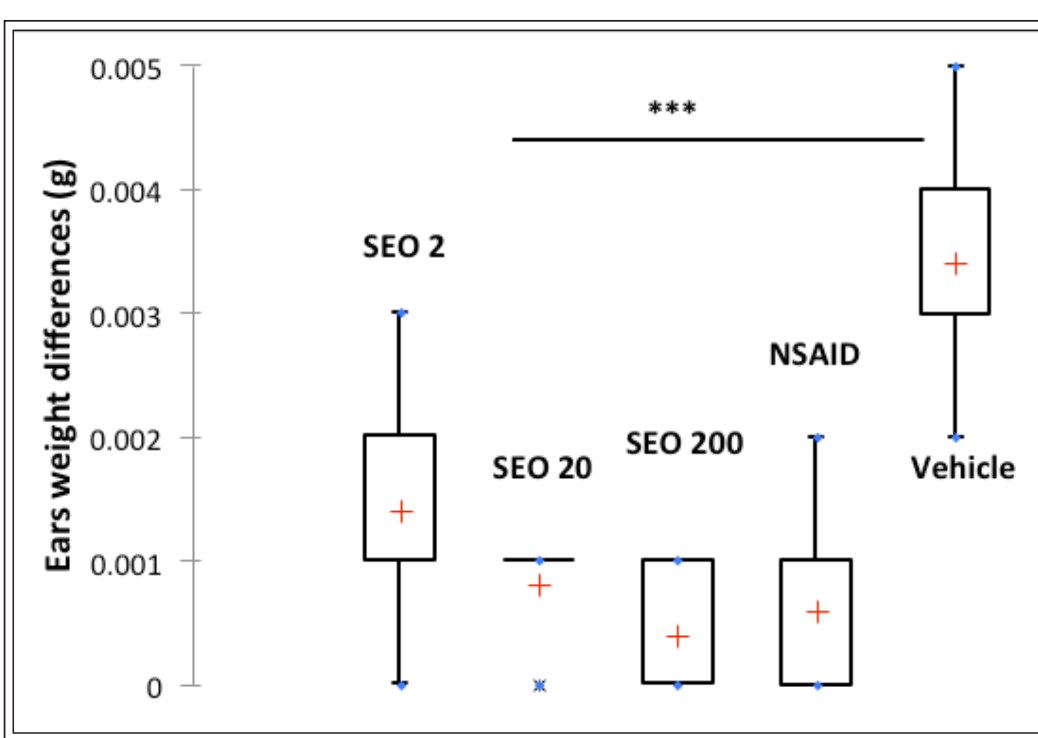

Figure 3 Topical anti-inflammatory effect of SEO in xylene-induced ear edema. Vehicle: control group (mice treated with almond oil topical application); SEO: mice treated with spearmint essential oil topically at different doses $(2,20$, and $200 \mu \mathrm{L} / \mathrm{kg})$ per ear; NSAID: mice treated with non-steroidal anti-inflammatory drugs (ketoprofen $2.5 \%$ ). Values represent the mean $\pm S E M .{ }^{* * *}$ significant difference $(p<0.001)$ according to ANOVA one-way analysis followed by

Tukey's post hoc multiple comparison tests.

a marked increase in the weight of the ears. However, the topical administration of the SEO $(200,20$ and $2 \mu \mathrm{L} / \mathrm{kg}), 40$ minutes before xylene application, decreased the development of ear edema. The inhibitory effect of the oil was similar to the inhibition caused by ketoprofen (Figure 3). Treat- ment of the mice with a high dose of SEO suppressed xylene-induced ear edema, reducing swelling by $94.44 \%$ $(p<0.001)$. The data indicate that SEO possesses inhibitory effects against acute inflammation.

Our findings revealed that SEO can markedly prevent the formation of xylene-induced ear edema. Mice ear edema may comprise the release of pro-inflammatory chemical mediators, increasing vascular permeability, leukocytes infiltration, plasma leakage and the production of cytokines such as interleukin $1 \beta$, tumor necrosis factor alpha (TNF $\alpha$ ) [24]. SEO may produce the anti-inflammatory action by influencing the actions of the above mediators [22,25].

NSAIDs are usually among the most used drugs in the treatment of inflammation. Unfortunately, the use of NSAIDs is restricted by several adverse effects and about $20 \%$ of patients will develop gastric ulcer [12]. Our study demonstrated that SEO showed similar effects with NSAIDs on the two models of inflammation (carrageenan and $x y-$ lene).

Table IV Study of anti-nociceptive activity of SEO by acetic acid-induced writhing test

\begin{tabular}{l|c|c}
\hline Treatment & $\begin{array}{c}\text { Number of writhing } \\
\text { (Mean } \pm \text { SD) \# }\end{array}$ & $\begin{array}{c}\text { Inhibition } \\
(\%)\end{array}$ \\
\hline Negative control (acetic acid) & $77.8 \pm 5.40^{\mathrm{B}}$ & - \\
\hline Positive control (Phloroglucinol) & $55.6 \pm 9.09^{\mathrm{A}}$ & $28.53^{* * *}$ \\
\hline SEO $200 \mu \mathrm{L} / \mathrm{kg}$ & $59.4 \pm 5.89^{\mathrm{A}}$ & $23.65^{* *}$ \\
\hline SEO $20 \mu \mathrm{L} / \mathrm{kg}$ & $65.2 \pm 3.96^{\mathrm{A}}$ & $16.19^{*}$ \\
\hline SEO $2 \mu \mathrm{L} / \mathrm{kg}$ & $65.24 \pm 3.96^{\mathrm{AB}}$ & $16.14^{\mathrm{ns}}$ \\
\hline
\end{tabular}

SEO: mice treated with spearmint essential oil at different doses $(2,20$, and $200 \mu \mathrm{L} / \mathrm{kg}, p .0)$. Values are expressed as mean \pm SD $\left(\mathrm{n}=6\right.$, per group); ${ }^{*} p<0.05 ;{ }^{* *} p<0.01 ;{ }^{* * *} p<0.001$. \# Means within the same column followed by the same capital letter are not significantly different $(p>0.05)$ according to ANOVA one way analysis followed by Tukey's post hoc multiple comparison test. 


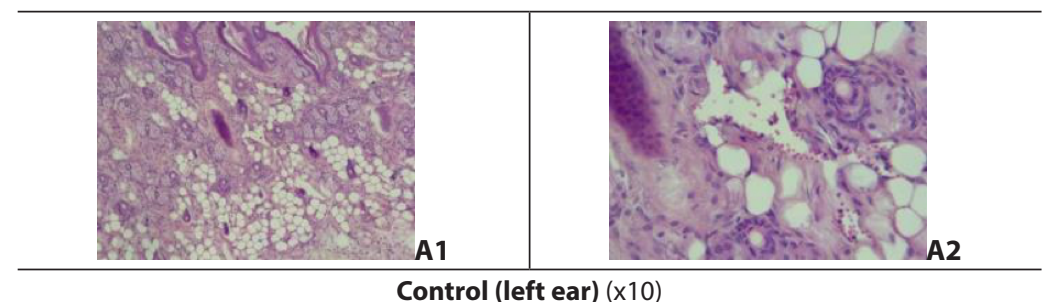

Edema (-); inflammatory cell infiltration (-), inflammation phase (-).
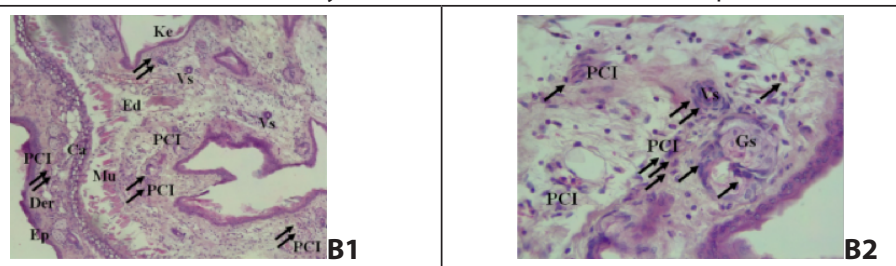

Negative control $=\lambda$-carrageenan group $((\mathrm{B} 1 \times 10 ; \mathrm{B} 2 \times 40)$

Congestion of vessels and a substantial number of infiltrated inflammatory cells. Edema $(++)$; inflammation phase (+++); inflammatory cell infiltration (+++) in epidermal and dermal layers, muscle and cartilage.
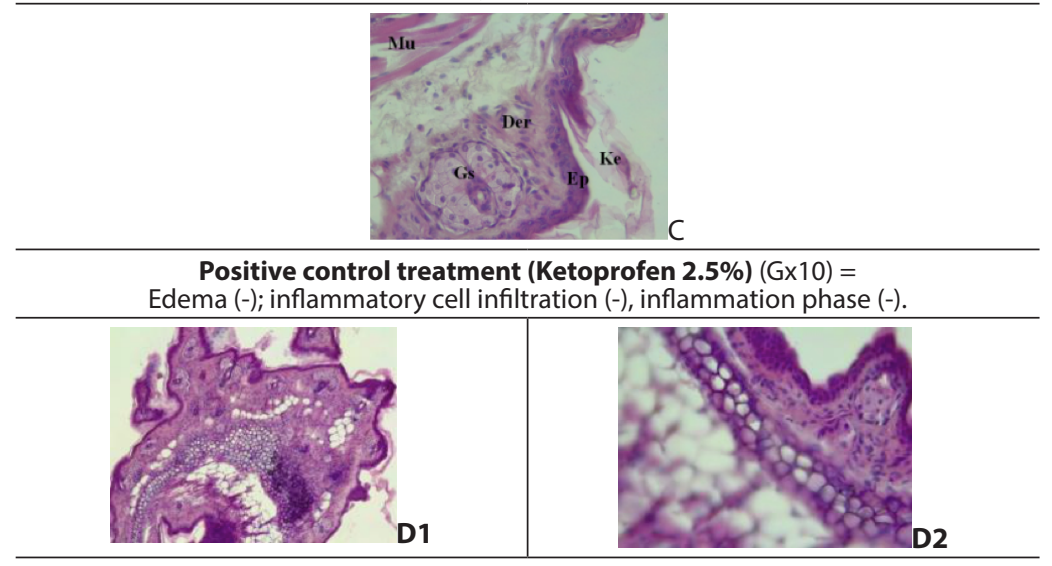

SEO treatment ( $2 \mu \mathrm{L} / \mathrm{Kg})(\mathrm{D} 1 \times 10$; D2 $\times 40)$

Edema (-); inflammatory cell infiltration (-), inflammation phase (-).

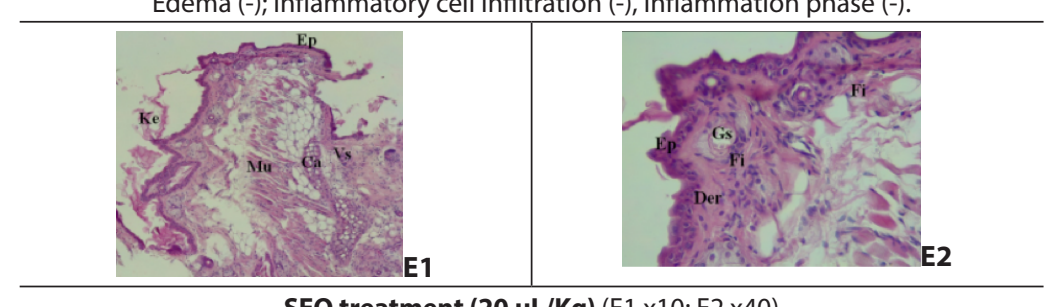

SEO treatment $(20 \mu \mathrm{L} / \mathrm{Kg})(\mathrm{E} 1 \times 10 ; \mathrm{E} 2 \times 40)$

Edema (-); inflammatory cell infiltration (-), inflammation phase (-).

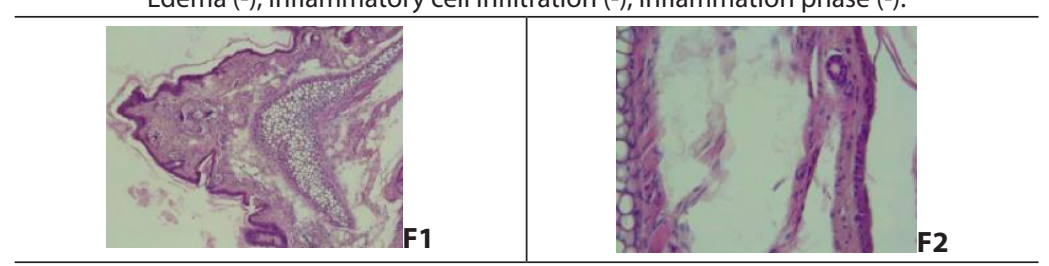

SEO treatment $(200 \mu \mathrm{L} / \mathrm{Kg})(\mathrm{F} 1 \times 10 ; \mathrm{F} 2 \times 40)$

Edema (-); inflammatory cell infiltration (-), inflammation phase (-).

Figure 4 Pathological examination of ear tissues after topical administration of xylene. Histopathology sections of mice ear biopsies showing keratin, epidermal, dermal, muscle, and cartilage layers. Hematoxylin \& Eosin stained sections were scored as mild (+), modest (++), and severe (++) for edema and substantial inflammatory polymorphonuclear cell infiltration (PCI) in the dermis inflammation phase.

(A) Normal Ear; (B) Control: Topical Application of xylene (20 $\mu$ L/ear) showed induced inflammatory lesion with edema and infiltration of polymorphonuclear leukocytes; (C) Ketoprofen decreased the indicated changes; Topical Application of the SEO at doses of 2 (D), 20 (E) and (F) $200 \mu \mathrm{L} / \mathrm{kg}$ after $4 \mathrm{~h}$ of topical xylene was able to decrease epidermis thickness, edema, and infiltration of polymorphonuclear leukocytes. Ke: keratin; Ep: epidermal layer; Bo: bone tissue; PCI: polymorphonuclear cells infiltration; Ed: edema; Mu: muscle.

\subsubsection{Examining the mouse ear tissue histology}

Anti-inflammatory effect of SEO on the carrageenan test led us to determine this effect in another neurogenic inflammatory assay (xylene-induced ear edema). We investigated H\&E stained ear sections from xylene-induced ear edema (Figure 4). By histological comparison, topical application of SEO decreased paw thickness and associated pathological indicators (Figure 4D, E and F) comparable to the positive control (ketoprofen gel) (Figure 4C).

The ear edema model induced by xylene has certain advantages in the determination of NSAIDs and has better predictive values in the screening of anti-inflammatory new molecules [23]. Xylene-induced swelling is followed by innate immunity reaction of the skin, a cytotoxicity response of activated $T$ cells followed by the migration of polymorphonuclear leucocytes which enhance inflammation and swelling of the ear. The pathological examination of inflamed tissues (paws and ears) showed that SEO inhibited infiltration of polymorphonuclear leucocytes into the site of inflammation. Therefore, another option is that SEO exerts its anti-edematous action partly through the inhibition of polymorphonuclear cell infiltration $[22,23,25]$. In addition, the chemical composition of SEO revealed the presence of high quantity of oxygenated terpene compounds such as carvone, menthol and eucalyptol. Literature review showed that the presence of these compounds in the SEO may be the main reason of its important anti-inflammatory property [21].

\subsection{In vivo effect of SEO on acetic acid-induced writhing response}

Acetic acid induced writhing experiment was done to evaluate the peripheral analgesic property of SEO. It is well known that acetic acid in some 


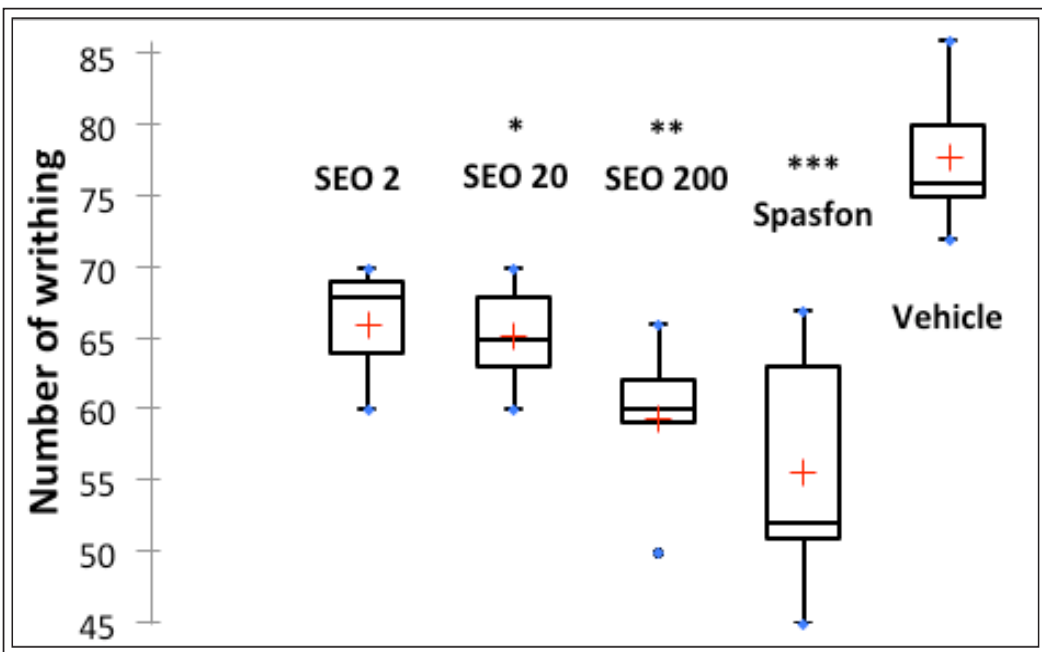

Figure 5 Anti-nociceptive activity of SEO in the acetic acid induced writhing test in vivo.

The effect of the SEO (2, 20 and $200 \mu \mathrm{L} / \mathrm{kg}$, i.p.), and Phloroglucinol (Spasfon $80 \mathrm{mg} / \mathrm{kg}$, i.p.) in the acetic-acid-writhing-induced nociception test in mice. Values are expressed as mean $\pm S D(n=6$, per group $) ;{ }^{*} p<0.05 ;{ }^{* *} p<0.01 ;{ }^{* * *} p<0.001$ significantly different from the control group, according to ANOVA, followed by Tukey's test.

way is responsible for secretion of endogenous mediators thereby stimulating the neurons responsible for pain perception, which are receptive to NSAIDs [26]. In this research, SEO showed a significant in vivo analgesic effect using the acetic acid-induced writhing test. Intraperitoneal (i.p) injection of acetic acid produced $77.8 \pm 5.40$ writhes in the solvent control group (Table IV and Figure 5). The writhing response was significantly decreased by pretreatment with $200 \mu \mathrm{L} / \mathrm{kg}$ of SEO $(77.8 \pm 5.40 ; p<0.01)$. Standard group which received Spasfon (Phloroglucinol) showed 28.53\% $\quad(p<0.001)$ of inhibition in writhing movement.

The analgesic properties of mint species have been studied and demonstrated by several authors $[12,27]$. In this study, we evaluated the antinociceptive effect of SEO using the acetic-acid induced pain model. The oral administration of SEO produced significant inhibition of the acetic acid-induced abdominal writhing in dose dependent manner in the mice, but the inhibition was similar to that produced by Phloroglucinol only at a higher dose $(200 \mu \mathrm{L} / \mathrm{kg})$. These data suggest that SEO may produce peripheral analgesic activity by inhibiting the chemical mediators and/ or cytokines (histamine, serotonin, bradykinin, cytokines, and eicosanoids). These mediators stimulate an increase of vascular permeability as well as reduce the threshold of nociception and stimulate the nervous terminal of nociceptive fibers $[7,23]$. The anti-inflammatory and anti-nociceptive activities of SEO may be related to the synergy interactions of its major or minor chemical components such as carvone, limonene and eucalyptol [28].

\section{Conclusion}

Our findings clearly confirmed that SEO has a potent peripheral analgesic activity and also demonstrated systemic and local anti-inflammatory properties in carrageenan and xylene models and these preliminary data could provide some credit for the potential use of spearmint as a bioactive agent for the treatment-prevention of inflammatory and painful conditions. Additional cellular and molecular assays will be done to investigate its real mechanisms of SEO including its active components such as carvone and limonene, alone or in combination, and to characterize the receptors involved in the antinociceptive and anti-inflammatory effects. A systemic study is required to produce nutraceuticals drug from SEO for treating various health problem of human kind.

\section{Sources of funding}

This research did not receive any specific grant from funding agencies in the public, commercial, or not for-profit sectors.

\section{Conflict of interest}

The authors declare that they have no conflict of interest.

\section{Ethics approval}

The experimental assay was agreed and approved by the European guidelines for animal handling and experiments.

\section{Acknowledgement}

The authors are grateful to SAIDAL pharmaceutical company (Research \& Development Center, Algiers, Algeria) for the excellent research facilities. The authors are grateful to the Hospital of Kolea (Tipaza, Algeria) for providing technical assistance in pathological analysis. 


\section{Authors' contributions}

Study concept and design: SK, MNB and MAF; Experiments: SK, $\mathrm{AB}$ and MNB; Analysis and interpretation of data: $\mathrm{SK}, \mathrm{AB}$ and $\mathrm{FB}$; Drafting of the manuscript: MNB, FB, and WS; and Critical revision of the manuscript for important intellectual content: SK and WS. All authors critically revised the article for important intellectual content and approved the final version.

\section{REFERENCES}

1. Jan, S., \& Khan, M. R. Antipyretic, analgesic and anti-inflammatory effects of Kickxia ramosissima. J Ethnopharmacol. 2016; 182: 90-100. https://doi. org/10.1016/j.jep.2016.02.020

2. Hotamisligil, G. S. Inflammation, metaflammation and immunometabolic disorders. Nature. 2017; 542: 177. https://doi.org/10.1038/nature21363

3. Laskin, D. L., \& Pendino, K. J. Macrophages and inflammatory mediators in tissue injury. Ann Rev Pharmacol Toxicol. 1995; 35: 655-677. https://doi. org/10.1146/annurev.pa.35.040195.003255

4. Shrihari, T. G. Dual role of inflammatory mediators in cancer. Ecancermedicalscience. 2017; 11: 721. https://doi.org/10.3332/ecancer.2017.721

5. Wongrakpanich, S., Wongrakpanich, A., Melhado, K., \& Rangaswami, J. A comprehensive review of non-steroidal anti-inflammatory drug use in the elderly. Aging Dis. 2018; 9: 143. http://dx.doi. org/10.14336/AD.2017.0306

6. Bruno, A., Tacconelli, S., \& Patrignani, P. Variability in the response to non-steroidal anti-inflammatory drugs: mechanisms and perspectives. Basic Clin Pharmacol Toxicol. 2014 ; 114: 56-63. https://doi. org/10.1111/bcpt.12117

7. Mahboubi, M. Mentha spicata as natural analgesia for treatment of pain in osteoarthritis patients. Compl. Therap. Clin Prac. 2017; 26: 1-4. https://doi. org/10.1016/j.ctcp.2016.11.001

8. Brahmi, F., Adjaoud, A., Marongiu, B., Falconieri, D., Yalaoui-Guellal, D., Madani, K., \& Chibane, M. Chemical and biological profiles of essential oils from Mentha spicata L. leaf from Bejaia in Algeria. J Essent Oil Res. 2016; 28: 211-220. https://doi.org/10.1 080/10412905.2015.1118411

9. Scherer, R., Lemos, M. F., Lemos, M. F., Martinelli, G. C., Martins, J. D. L., \& da Silva, A. G. Antioxidant and antibacterial activities and composition of Brazilian spearmint (Mentha spicata L.). Ind Crops Prod. 2013 ; 50: 408-413. https://doi.org/10.1016/j.indcrop.2013.07.007

10. Nikšić, H., Durić, K., Omeragić, E., Nikšić, H., Muratović, S., \& Bečić, F. Chemical characterization, antimicrobial and antioxidant properties of Mentha spicata L.(Lamiaceae) essential oil. Bull Chem Technol Bosn Herzeg. 2018; 43-48.

11. Bardaweel, S. K., Bakchiche, B., ALSalamat, H. A., Rezzoug, M., Gherib, A., \& Flamini, G. Chemical composition, antioxidant, antimicrobial and antiproliferative activities of essential oil of Mentha spicata L.(Lamiaceae) from Algerian Saharan atlas. BMC Compl Altern Med. 2018; 18: 201. https://doi. org/10.1186/s12906-018-2274-x

12. Mogosan, C., Vostinaru, O., Oprean, R., Heghes, C., Filip, L., Balica, G., \& Moldovan, R. I. A comparative analysis of the chemical composition, anti-inflammatory, and antinociceptive effects of the essential oils from three species of Mentha cultivated in Romania. Molecules. 2017; 22: 263. https://doi. org $/ 10.3390 /$ molecules22020263

13. Boukhatem, M. N., Ferhat, M. A., Kameli, A., Saidi, F., \& Kebir, H. T. Lemon grass (Cymbopogon citratus) essential oil as a potent anti-inflammatory and antifungal drugs. Libyan J Med. 2014; 9: 25431. https://doi.org/10.3402/ljm.v9.25431

14. Govindarajan, M., Sivakumar, R., Rajeswari, M., \& Yogalakshmi, K. Chemical composition and larvicidal activity of essential oil from Mentha spicata (Linn.) against three mosquito species. Parasitol Res. 2012; 110: 2023-2032. https://doi.org/10.1007/ s00436-011-2731-7

15. Padalia, R. C., Verma, R. S., Amit, C., Velusamy, S., \& Chanotiya, C. S. Essential oil composition of sixteen elite cultivars of Mentha from western Himalayan region, India. Maejo Int J Sci Technol. 2013; 7: 83-93. https://doi.org/10.14456/mijst.2013.7

16. Telci, I., Demirtas, I., Bayram, E., Arabaci, O., \& Kacar, O. Environmental variation on aroma components of pulegone/piperitone rich spearmint (Mentha spicata L.). Ind Crops Prod. 2010; 32: 588-592. https://doi.org/10.1016/j.indcrop.2010.07.009

17. El-Sayed, Z. I. A., Omar, N. A., \& Romeh, A. A. Chemical constituents and biocidal activity of the essential oil of Mentha spicata L. grown in Zagazig region, Egypt. Res J Agr Biol Sci. 2009; 5; 1089-1097.

18. Baser, K. H. C., Kürkçüoglu, M., Tarimcilar, G., \& Kaynak, G. Essential oils of Mentha species from Northern Turkey. J Essent Oil Res. 1999; 11:, 579-588. https://doi.org/10.1080/10412905.1999.9701218

19. Yahia, I. B. H., Jaouadi, R., Trimech, R., Boussaid, M., \& Zaouali, Y. Variation of chemical composition and antioxidant activity of essential oils of Mentha x rotundifolia (L.) Huds.(Lamiaceae) collected from different bioclimatic areas of Tunisia. Biochem Syst Ecol. 2019; 84: 8-16. https://doi.org/10.1016/j.bse.2019.03.001

20. Zhao, M., \& Du, J. Anti-inflammatory and protective effects of D-carvone on lipopolysaccharide (LPS)-induced acute lung injury in mice. J King Saud UnivSci. 2019; https://doi.org/10.1016/j.jksus.2019.12.016

21. Andrade, L. N., \& De Sousa, D. P. A review on antiinflammatory activity of monoterpenes. Molecules. 2013; 18: 1227-1254. https://doi.org/10.3390/molecules18011227

22. Arumugam, P., Priya, N. G., Subathra, M., \& Ramesh, A. Anti-inflammatory activity of four solvent fractions of ethanol extract of Mentha spicata L. investigated on acute and chronic inflammation induced rats. Envir Toxicol Pharmacol. 2008; 26: 92-95. https://doi.org/10.1016/j.etap.2008.02.008 
23. Yousuf, P. M. H., Noba, N. Y., Shohel, M., Bhattacherjee, R., \& Das, B. K. Analgesic, anti-inflammatory and antipyretic effect of Mentha spicata (Spearmint). J Pharm Res Int. 2013; 854-864. https://doi. org/10.9734/BJPR/2013/4640

24. Saito, A., Tanaka, H., Usuda, H., Shibata, T., Higashi, S., Yamashita, H., \& Nagai, H. Characterization of skin inflammation induced by repeated exposure of toluene, xylene, and formaldehyde in mice. Envir Toxicol. 2011; 26: 224-232. https://doi.org/10.1002/ tox.20547

25. Pearson, W., Fletcher, R. S., Kott, L. S., \& Hurtig, M. B. Protection against LPS-induced cartilage inflammation and degradation provided by a biological extract of Mentha spicata. BMC Complem Altern Med. 2010; 10: 19. https://doi.org/10.1186/1472-6882-10-19
26. Lenardão, E. J., Savegnago, L., Jacob, R. G., Victoria, F. N., \& Martinez, D. M. Antinociceptive effect of essential oils and their constituents: an update review. J Braz Chem Soc. 2016; 27: 435-474. https://doi. org/10.5935/0103-5053.20150332

27. Sousa, P. J. D. C., Linard, C. F. B. M., Azevedo-Batista, D., Oliveira, A. C., Coelho-de-Souza, A. N., \& Leal-Cardoso, J. H. Antinociceptive effects of the essential oil of Mentha x villosa leaf and its major constituent piperitenone oxide in mice. Braz J Med Biol Res. 2009; 42: 655-659. https://doi.org/10.1590/ S0100-879X2009000700010

28. de Sousa, D. P., Mesquita, R. F., de Araújo Ribeiro, L. A., \& de Lima, J. T. Spasmolytic activity of carvone and limonene enantiomers. Nat Prod Comm. 2015 ; 10. https://doi.org/10.1177/1934578X1501001120 